\title{
Controle Interno na Administração Pública: um estudo de caso em uma Empresa de Médio Porte
}

\author{
Internal Control in Public Administration: a case study in a Medium-Sized Company \\ Control Interno en la Administración Pública: un estudio de caso en una Mediana Empresa
}

Recebido: 03/02/2022 | Revisado: 08/02/2022 | Aceito: 12/02/2022 | Publicado: 18/02/2022

Luana Mayara Sousa Santos

ORCID: https://orcid.org/0000-0002-1303-4002 Centro Universitário Estácio de Sergipe, Brasil

E-mail: luanamsousa27@gmail.com

Cleide Ane Barbosa da Cruz

ORCID: https://orcid.org/0000-0002-8277-1460 Centro Universitário Estácio de Sergipe, Brasil

E-mail: cleianebar@gmail.com

Joenison Batista da Silva

ORCID: https://orcid.org/0000-0001-5202-4782 Centro Universitário Estácio de Sergipe, Brasil

E-mail: joenison.silva@estacio.br

Raquel Nominato Araújo

ORCID: https://orcid.org/0000-0002-5075-3268 Instituto Federal de Educação, Ciência e Tecnologia de Sergipe, Brasil

E-mail: raquel.araujo@ifs.edu.br

\begin{abstract}
Resumo
O controle interno contribui positivamente no processo de gestão da administração pública, visto que assegura que a atuação administrativa seja realizada de forma eficiente. Por isso, esta pesquisa tem como objetivo analisar como o controle interno pode contribuir para a administração pública de uma empresa de médio porte. A metodologia consiste numa pesquisa exploratória quantitativa que realizou a aplicação de um questionário com perguntas fechadas aos colaboradores da empresa, sendo que este foi enviado via e-mail, tendo um retorno de 53 colaboradores da empresa. Os resultados indicaram que os colaboradores estão cientes das contribuições e do papel importante que o controle interno desempenha na empresa, sendo que a maioria dos entrevistados conhecem totalmente as contribuições da utilização do controle interno na execução das atividades da organização. Dessa forma, o estudo apontou que é necessário dedicar uma maior atenção no tocante às práticas de prevenção à fraude e à corrupção, visando contribuir com a melhoria da gestão da empresa estudada.
\end{abstract}

Palavras-chave: Eficiência; Gestão; Processos.

\begin{abstract}
Internal control contributes positively to the management process of public administration, as it ensures that administrative action is carried out efficiently. Therefore, this research aims to analyze how internal control can contribute to the public administration of a medium-sized company. The methodology consists of a quantitative exploratory research that carried out the application of a questionnaire with closed questions to the company's employees, which was sent via e-mail, with a return of 53 company employees. The results indicated that employees are aware of the contributions and the important role that internal control plays in the company, and most respondents are fully aware of the contributions of the use of internal control in the execution of the organization's activities. In this way, the study pointed out that it is necessary to devote greater attention to fraud and corruption prevention practices, aiming to contribute to the improvement of the management of the studied company.
\end{abstract}

Keywords: Efficiency; Management; Process.

\section{Resumen}

El control interno contribuye positivamente al proceso de gestión de la administración pública, ya que asegura que la acción administrativa se lleve a cabo de manera eficiente. Por lo tanto, esta investigación tiene como objetivo analizar cómo el control interno puede contribuir a la gestión pública de una mediana empresa. La metodología consiste en una investigación exploratoria cuantitativa que llevó a cabo la aplicación de un cuestionario con preguntas cerradas a los trabajadores de la empresa, el cual fue enviado vía correo electrónico, con un retorno de 53 trabajadores de la empresa. Los resultados indicaron que los empleados son conscientes de las contribuciones y el papel importante que juega el control interno en la empresa, y la mayoría de los encuestados son plenamente conscientes de las contribuciones del uso del control interno en la ejecución de las actividades de la organización. De esta forma, el 
estudio señaló que es necesario dedicar mayor atención a las prácticas de prevención del fraude y la corrupción, con el objetivo de contribuir a la mejora de la gestión de la empresa estudiada.

Palabras clave: Eficiencia; Gestión; Proceso.

\section{Introdução}

Quando se fala sobre controle interno, sua área de atuação é primeiramente relacionada a ilegalidades, prevenção de fraudes e corrupção. Pouco se fala sobre a importância deste sistema nos processos rotineiros de uma instituição, e sobre como a adoção desta ferramenta pode aprimorar o gerenciamento e a eficácia das organizações. Castro (2014, p.134) relata que “[...] o controle interno tem por objetivo - ao recair sobre todos os atos e procedimentos administrativos do ente controlado assegurar a execução segura da atuação administrativa, pautada em princípios e regras técnicas e de direito, com vistas à realização precípua do interesse público".

Assim, é compreensível que o controle interno possa tornar o processo de gestão mais favorável não somente quanto à ilegalidades e prevenção de fraudes, mas também dentro das atividades frequentes de uma organização. Desta maneira, a partir de pesquisas aplicadas e análises de materiais corporativos e acadêmicos, buscou-se evidenciar esta premissa, de ressaltar o papel do controle interno, sobretudo na administração pública, visando demonstrar a importância e benefícios desta ferramenta de governabilidade que pode aprimorar a eficiência e flexibilidade na gestão, a fim de realizar e manter o interesse público.

Ainda, o intuito deste estudo é analisar, reforçar a importância do Controle Interno dentro de uma organização, e mostrar como a prática desta atividade pode ser benéfica, tornando o processo de gestão mais seguro, eficiente e contribuindo ativamente no alcance dos objetivos da instituição, pois de acordo com Brumen, Silva e Saltes (2015, p.11) “[...] sem um sistema de controle, por mais simplificado que ele seja, muito provavelmente as organizações podem ou poderão ser vítimas de fraudes, erros, inconsistências, desvios, ineficiências e fracassos”. Diante disso, este trabalho tem como problema: Como o controle interno pode contribuir para a administração pública em uma empresa de médio porte?

Para responder a este questionamento, esta pesquisa tem como objetivo analisar como o controle interno pode contribuir para a administração pública de uma empresa de médio porte.

\section{Marco teórico}

\subsection{Administração Pública}

A Administração Pública é o aparelhamento do Estado, organizado para a realização de seus serviços, visando à satisfação das necessidades coletivas (Silva, 2017, p. 3).

Ainda, para Costa e Terra (2008, p. 220):

Falar em Administração Pública é antes de mais nada aclarar o que venha ser a sua própria designação, mesmo que o objeto deste não seja o exaurimento do assunto, mas de forma introdutória para a melhor compreensão do pleito do mesmo. Dessa forma, pode-se visualizá-la de dois modos, quais sejam em sentido amplo e, em sentido restrito.

* Sentido Amplo: referindo-se ao próprio Estado, ou seja, como um conjunto de órgãos e entidades incumbidos da realização da atividade administrativa, no intuito real de cumprimento das finalidades do Estado [...]. Ademais, tecnicamente, o termo Administração encerra qualquer dos Poderes do Estado no cumprimento de sua função administrativa.

* Sentido Estrito: aludindo-se ao exercício da atividade administrativa exercida pelos entes da Administração, ou seja, é o Estado agindo, administrando. Aqui temos administração pública, como atividade desenvolvida pelo Estado. Em outras palavras, significa dizer que o conceito de Administração Pública em sentido estrito "não alcança a função política de Governo, de fixação de planos e diretrizes governamentais, mas tão somente a função propriamente administrativa, de execução de atividades administrativas", ou seja, ela é voltada para os órgãos que desempenham funções administrativas.

Além disso, Bachtold (2008) afirma que a definição de administração pública é o planejamento, organização, direção 
e controle dos serviços públicos em prol do bem comum, de acordo com as normas do direito e da moral. Ele também diz que a função básica da administração é fazer as coisas por meio das pessoas, de modo eficiente e eficaz, sempre mantendo o interesse público acima do interesse particular.

Ainda, atualmente percebe-se que a administração pública procura por meio da privatização e revalorização da sociedade civil por meio de um procedimento de concessão em que um serviço particular é contratado para realizar um atividade de cunho coletivo, como por exemplo, serviços de saúde, educação, transporte, entre outros (Sinay et al., 2020).

Diante destes contextos a administração pública é definida como o Estado em si, isto é, todos os órgãos e instituições responsáveis por fazer cumprir-se a atividade administrativa na esfera pública; também é vista como o próprio processo administrativo, a própria função definida pelo Estado; e ainda há a administração pública como objeto de estudo, área de conhecimento. Em todos os casos o seu propósito é o de gerir o patrimônio público e satisfazer os direitos e interesses da sociedade, sempre pautando suas atividades na lei.

\subsection{Controle Interno}

Lima et al. (2012) afirmam que um bom controle interno agrega valor à organização e assegura confiabilidade aos clientes, fornecedores e investidores, pois permite que sejam identificados rapidamente os fatores internos e externos que possam impactar os negócios da empresa, tanto nas operações, na lucratividade, no seu ativo e passivo.

Em complemento, Almeida (2010) explica que o controle interno tem o objetivo de proteger os ativos, transformando as informações contábeis em confiáveis e transparentes, o que possibilita que a administração obtenha esses dados visando orientar os gestores na continuidade das Entidades. Ademais, Pagliato (2011) destaca que o controle interno também busca descrever as medidas que são tomadas pela administração de empresas, visando realizar a direção, preparação e controle dos negócios de uma organização.

Ainda, para Lima et al. (2012, p. 3):

Controle Interno são medidas constantes realizadas pela empresa para promover resultados eficientes nas atividades operacionais, protegendo o patrimônio e salvaguardando os bens e os direitos quanto a possíveis erros e fraudes, tornando os dados confiáveis, garantindo a continuidade do fluxo das operações para alcançar os objetivos, minimizando perdas e riscos que possam comprometer a continuidade da empresa no mercado em que se está inserida.

Por sua vez, para Moura e Barbosa (2016), o controle interno é um conjunto de técnicas que buscam compreender o plano de estruturação das organizações, protegendo o patrimônio, verificando a contabilidade e assegurando boas práticas de gestão, pois uma vez que as informações se mostrem adulteradas, podem prejudicar a notoriedade da instituição.

Lunkes (2007) afirma que o controle interno é um recurso essencial para o ciclo administrativo, pois têm a finalidade de controlar o desenvolvimento das atividades, se certificando que as práticas sejam realizadas como planejado. Para Fontes Filho e Alves (2018, p. 5) "o controle interno das empresas ocorre no nível de seus órgãos sociais, designadamente a assembleia-geral, o conselho de administração e o conselho fiscal ou similar. Além disso, as empresas são sujeitas às auditorias externa e interna".

Já para da Silva (2002), o controle interno é formado pelo plano de organização e todas as formas pelas quais as organizações controlam suas obrigações, buscando garantir a proteção do patrimônio, exatidão e veracidade dos dados contábeis, e a eficiência operacional, como meios para atingir os objetivos da instituição. Procópio Júnior et al. (2012) explica que é por meio do controle interno que a administração obtém informações de toda organização, buscando visualizar se as metas traçadas estão sendo seguidas de acordo com o que foi planejado.

Ainda, segundo Pereira (2004), 
[...] ]os objetivos do controle interno contemplam:

a) dotar a empresa de uma base informativa confiável e tempestiva;

b) induzir comportamento focado em resultados;

c) salvaguardar o potencial de geração de riqueza (patrimônio); e

d) garantir, subsidiariamente, observância de regulação aplicável à firma.

Nota-se que os autores citados consideraram que o controle interno possui enorme utilidade para avaliar os processos de gestão. Nos conceitos apresentados, é perceptível a existência de pontos relacionados à direção e a aspectos econômicos e financeiros. Assim, com base nas literaturas estudadas, observou-se uma grande relação entre controle interno e gestão empresarial, onde ao implantar o controle interno dentro da organização, haverá a melhoria e aprimoramento nos processos habituais de governança.

\section{Metodologia}

A metodologia é a maneira como o estudo é realizado, e por sua vez descreve os fundamentos metodológicos que apoiam a base para evolução da pesquisa. De acordo com Gil (2021), é possível classificar as pesquisas em: exploratórias, descritivas e explicativas. Gil (2017) ainda acrescenta que as pesquisas exploratórias têm como propósito proporcionar maior familiaridade com o problema, visando torná-lo mais explícito ou a construir hipóteses.

Para Richardson (1999), a pesquisa quantitativa tem como característica o uso da quantificação, tanto na coleta de informações quanto no tratamento delas por meio de métodos estatísticos.

Desse modo, o método de pesquisa realizado foi exploratório, quantitativo e de campo, pois neste tipo de procedimento a pesquisa é desenvolvida por meio da observação direta das atividades e de entrevistas com indivíduos para colher suas explicações e interpretações. Os dados foram coletados, também, através dos arquivos disponibilizados para consulta no acervo digital da organização.

Além disso, utilizou-se como instrumento de coleta de dados um questionário com perguntas fechadas, com o intuito de analisar o nível de conhecimento dos colaboradores sobre a área de controle interno dentro da organização e a importância das suas ações. O questionário foi elaborado de forma digital, através da ferramenta Google Forms, com 11 questões relacionadas aos objetivos específicos, e foi aplicado aos colaboradores da empresa em geral.

O envio do questionário foi realizado via e-mail e obteve um alcance de 53 pessoas. Todos foram validados, atingindo um percentual de $100 \%$ de aproveitamento. Os colaboradores foram questionados, primeiramente, sobre a sua caracterização pessoal e profissional, e em seguida, sobre a percepção da ocupação e práticas do controle interno na instituição.

A duração da pesquisa, incluindo a coleta, análise e registro dos resultados, teve início no dia 03/11/2021 e foi concluída em 18/11/2021. O período total foi de 15 (quinze) dias, onde foram 12(doze) dias para a coleta dos dados e outros 3 (três) dias para análise e documentação dos resultados obtidos.

\section{Resultados e Discussão}

Para a fundamentação do objeto de estudo, foi aplicado um questionário onde foram abordados temas relacionados à caracterização pessoal, profissional, e sobre a percepção da ocupação e práticas do controle interno na organização. A Figura 1 apresenta o gênero dos colaboradores. 
Figura 1: Gênero dos Colaboradores.

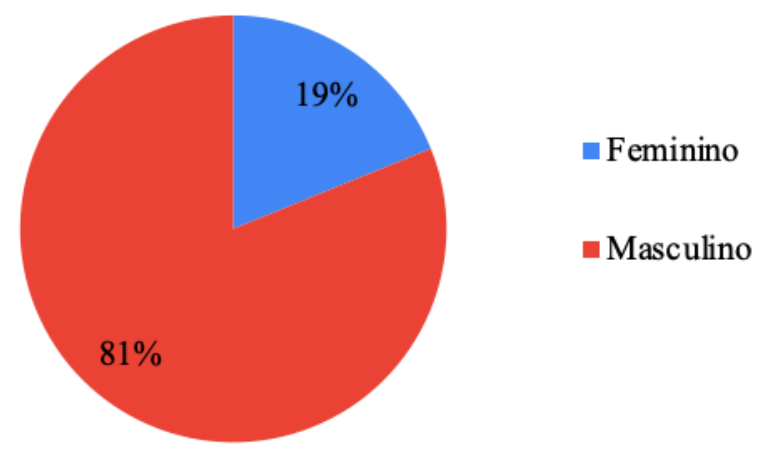

Fonte: Autores (2021).

Quando questionados sobre a qual gênero pertenciam, pôde ser observado que a maioria dos colaboradores que responderam à pesquisa são do sexo masculino. De acordo com a Figura 1, das 53 respostas obtidas apenas 10 representam o sexo feminino, o equivalente a $19 \%$ do total. Já do sexo masculino foram 43, ou seja, $81 \%$. Na Figura 2 estão destacadas as idades dos colaboradores.

Figura 2: Idade dos Colaboradores.

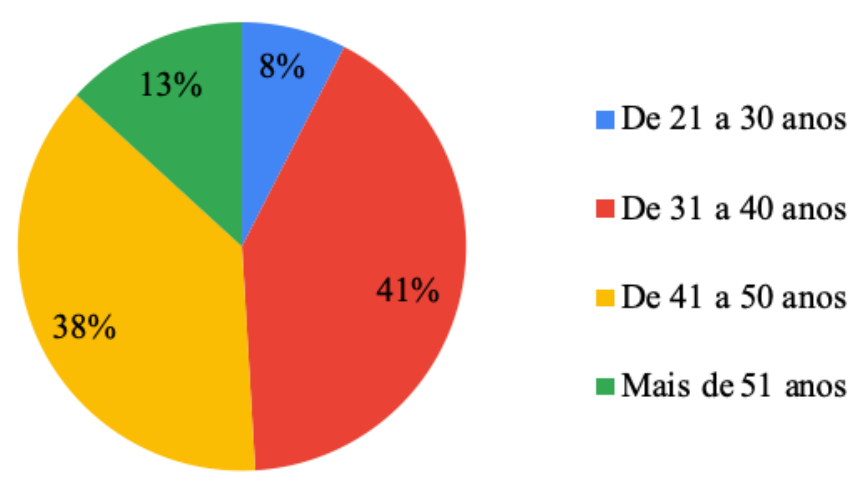

Fonte: Autores (2021).

A Figura 2 destaca que dos 53 colaboradores que responderam à pesquisa, não havia nenhum com menos de 20 anos. Com idade entre 21 e 30 anos foram apenas 4 pessoas, correspondentes a $8 \%$ do total; os participantes com idade de 31 a 40 anos foram 22, ou seja, $41 \%$; com idade entre 41 e 50 anos o total de colaboradores foi de 20, totalizando $38 \%$; e com mais de 51 anos houveram 7 participantes, contabilizando $13 \%$ de um total de 100\%. Por sua vez, a Figura 3 apresenta o cargo que os colaboradores ocupam na empresa. 
Figura 3: Cargo que ocupa na empresa.

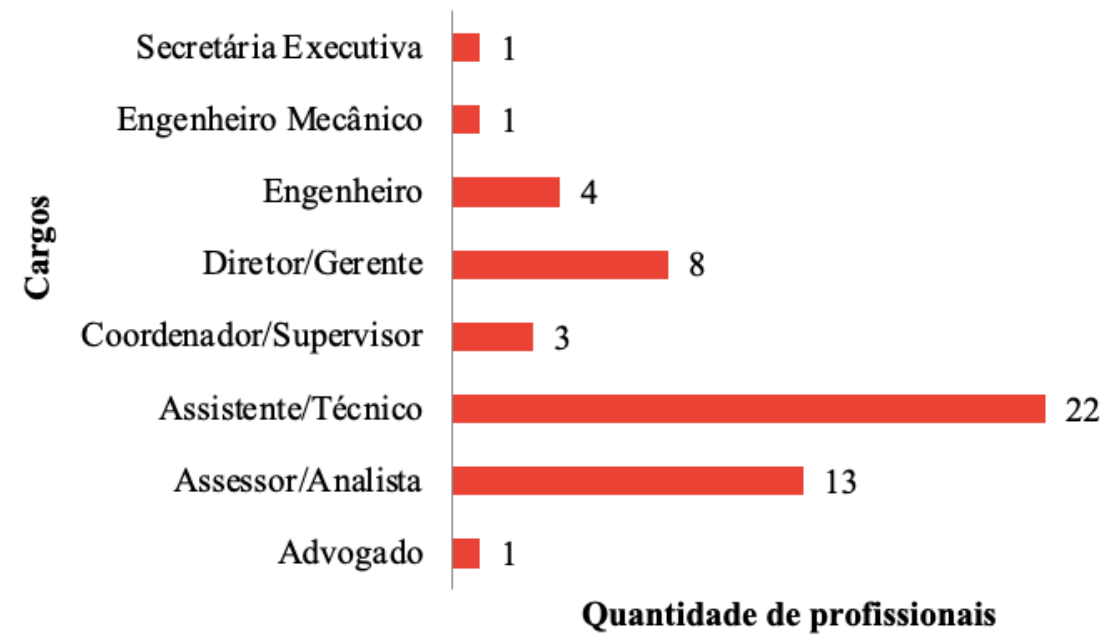

Fonte: Autores (2021).

Quando os colaboradores foram questionados sobre o cargo que ocupam atualmente na empresa, percebeu-se na Figura 3 que estes destacaram que há 1(uma) secretária executiva, 1(um) engenheiro mecânico, 4(quatro) engenheiros, 8(oito) diretores/gerentes, 3(três) coordenadores/supervisores, 22(vinte e dois) assistentes/técnicos, 13(treze) assessores/analistas e 1(um) advogado. Ainda, a Figura 4 destaca o tempo que foi investido no cargo.

Figura 4: Tempo investido no cargo.

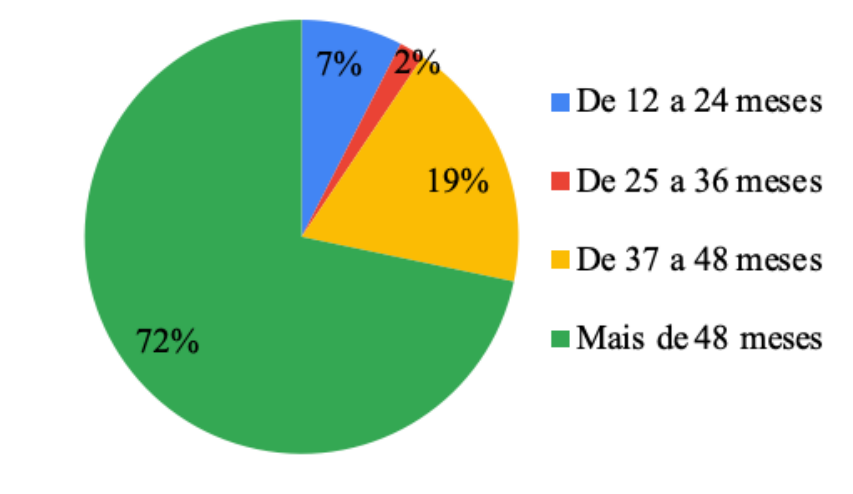

Fonte: Autores (2021).

Sobre o tempo investido no cargo, observou-se que das 53 respostas obtidas, 4 (7\%) dos colaboradores destacaram que estão no cargo que ocupam de 12 a 24 meses, apenas 1 (2\%) colaborador está alocado no cargo atual de 25 a 36 meses; 10 (19\%) dos colaboradores estão entre 37 a 48 meses no cargo e 38 (72\%) colaboradores estão ocupando o cargo atual há mais de 48 meses. A Figura 5 destaca o conhecimento dos colaboradores sobre o que vem a ser controle interno. 
Figura 5: Conhecimento sobre o que vem a ser Controle Interno.

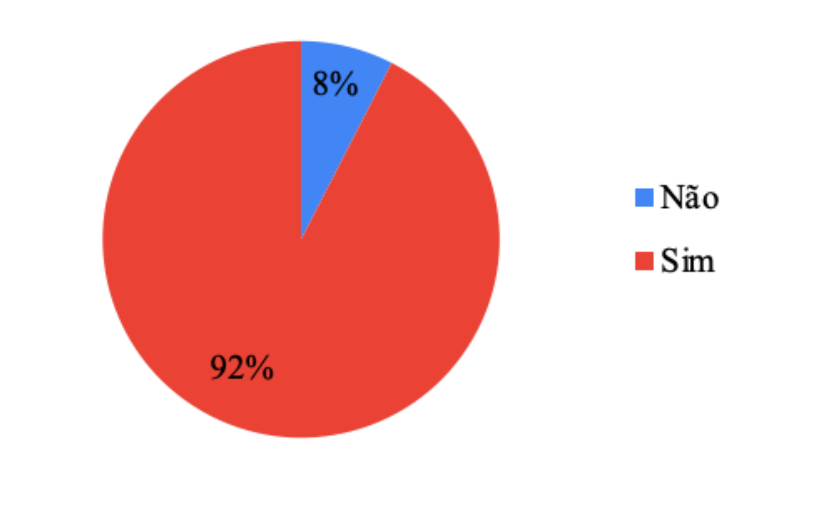

Fonte: Autores (2021).

Quando perguntado aos colaboradores se eles sabiam o que é o controle interno, notou-se que a maioria dos colaboradores, um total de $92 \%$, responderam que sabiam o que é controle interno e somente 4 colaboradores, respectivamente $8 \%$ do total, disseram não saber o que é o controle interno.

Em complemento, Lima et al. (2012) explica que o controle interno possibilita que as atividades de uma organização se desenvolvam com uma maior eficiência, trazendo maior regularidade as operações, adequação dos registros e controles, determinando assim seus reflexos nas demonstrações financeiras das empresas. Ademais, a Figura 6 envolve o conhecimento dos colaboradores sobre a localização do controle interno no organograma da empresa.

Figura 6: Conhecimento sobre a localização do controle interno no organograma da empresa.

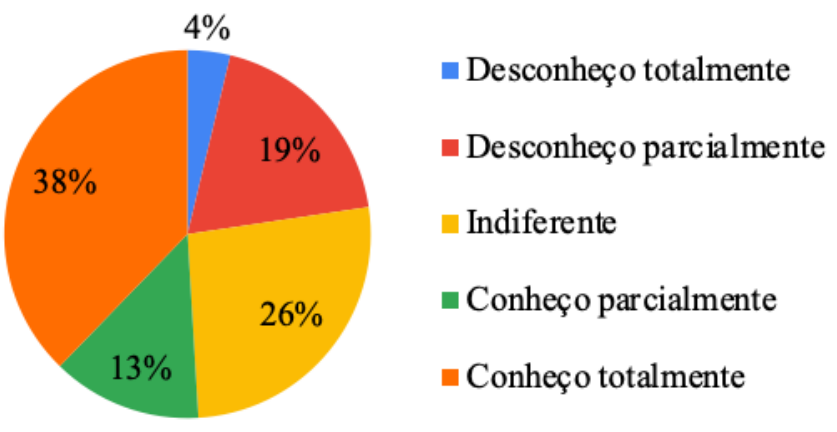

Fonte: Autores (2021).

Ainda, notou-se que os colaboradores foram questionados se conheciam a localização do controle interno no organograma da organização. Conforme mostra a Figura 6, 4\% dos colaboradores responderam que desconhecem totalmente a localização do controle interno no organograma da organização, $19 \%$ responderam que desconhecem parcialmente, $26 \%$ responderam que são indiferentes; $13 \%$ responderam que conhecem parcialmente; e 38\% disseram que conhecem totalmente a localização do controle interno no organograma da organização.

Os colaboradores também foram interrogados sobre o quanto compreendiam a função do controle interno dentro da empresa, sendo que em sua maioria responderam que conhecem totalmente. No entanto, a Figura 7 apresenta a função do controle interno na empresa. 
Figura 7: Função do Controle Interno na Empresa.

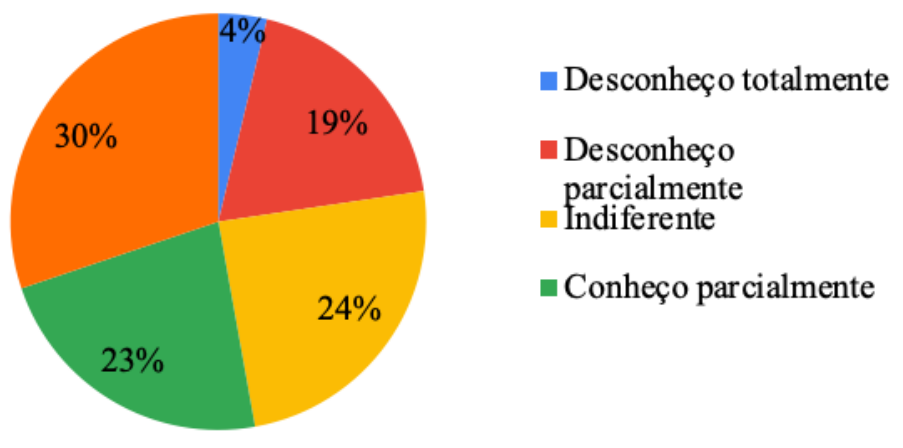

Fonte: Autores (2021).

A Figura 7 evidenciou que dos 53 colaboradores, $4 \%$ responderam que não compreendem a função do controle interno na empresa; $19 \%$ dos colaboradores disseram que desconhecem parcialmente; $24 \%$ responderam ser indiferentes; $23 \%$ responderam que conhecem parcialmente; e os que compreendem totalmente o papel do controle interno dentro da organização somaram $30 \%$.

Para Novo (2019) a missão do controle interno é buscar oferecer aos gestores informações que o auxiliaram na tomada de decisão, bem como relatos que podem contribuir para o controle dos processos, visando alcançar as metas organizacionais. Por sua vez, a Figura 8 destaca o papel do controle interno.

Figura 8: Papel do controle interno.

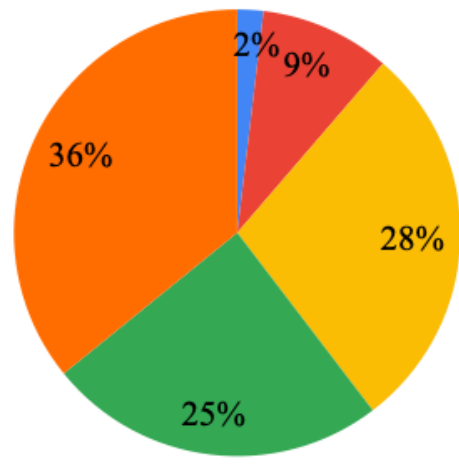

ఐ Desconheço totalmente

- Desconheço parcialmente

Indiferente

- Conheço parcialmente

ఐ Conheço totalmente

Fonte: Autores (2021).

A Figura 8 procurou destacar quanto os colaboradores consideravam o papel do controle interno essencial dentro da empresa. Percebeu-se nos resultados que apenas $2 \%$ responderam que desconhecem totalmente ser essencial o papel do controle interno na empresa; 9\% responderam que desconhecem parcialmente; $28 \%$ responderam que são indiferentes; $25 \%$ conhecem parcialmente ser essencial a função do controle interno na empresa; e 36\% conhecem totalmente sobre o dever do controle interno dentro da organização. 
Ainda, Crepaldi e Crepaldi (2014) destaca que o controle interno busca proporcionar segurança quanto ao alcance dos objetivos como confiabilidade e rapidez nas informações, bem como obediência nas leis. Ademais, a Figura 9 traz o conhecimento dos colaboradores quanto às contribuições da utilização do controle interno.

Figura 9: Conhecimento das contribuições da utilização do controle interno.

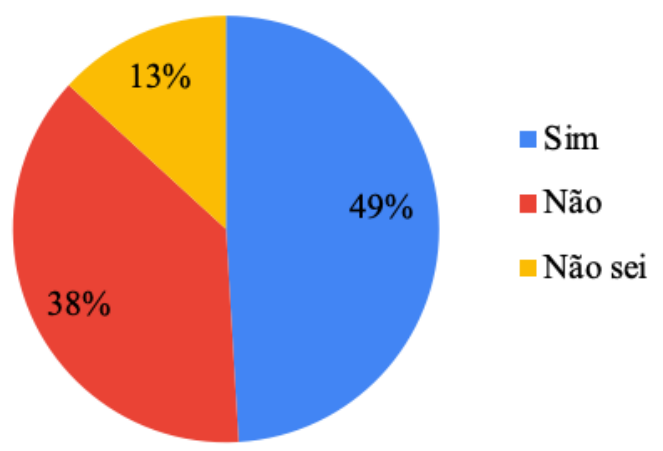

Fonte: Autores (2021).

Quando perguntado se possuíam conhecimento de alguma das contribuições da utilização do controle interno na execução das atividades da empresa, a maioria dos colaboradores, $49 \%$ responderam que sim, 38\% disseram não saber de nenhuma das contribuições da utilização do controle interno na empresa e apenas $13 \%$ não souberam responder. Por sua vez, a Figura 10 destaca a influência do controle interno no setor de trabalho.

Figura 10: Influência do controle interno no setor de trabalho.

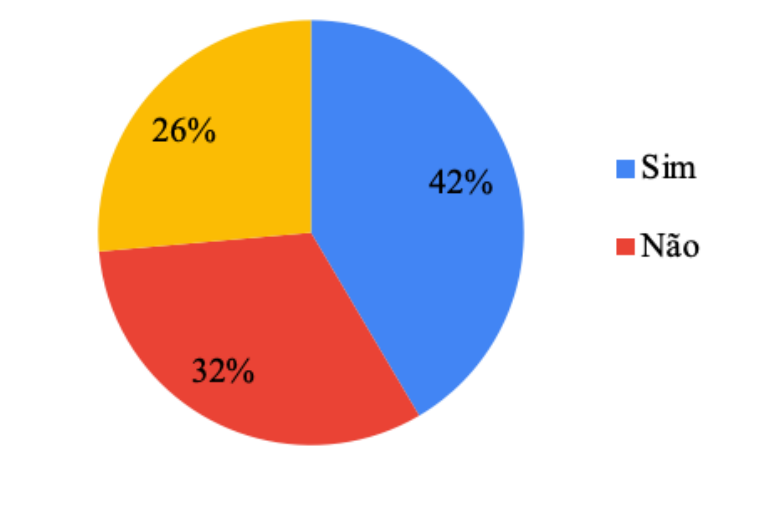

Fonte: Autores (2021).

Além disso, os colaboradores também foram indagados se a atuação do controle interno teria influência no setor em que trabalham e a Figura 10 apresenta que 42\% dos colaboradores disseram que sim, 32\% responderam que não e 26\% afirmaram não saber se a atuação do controle interno teria influência no setor em que trabalham. Por sua vez, a Figura 11 traz o favorecimento do controle interno na gestão de processos. 
Figura 11: Favorecimento do controle interno na gestão de processos.

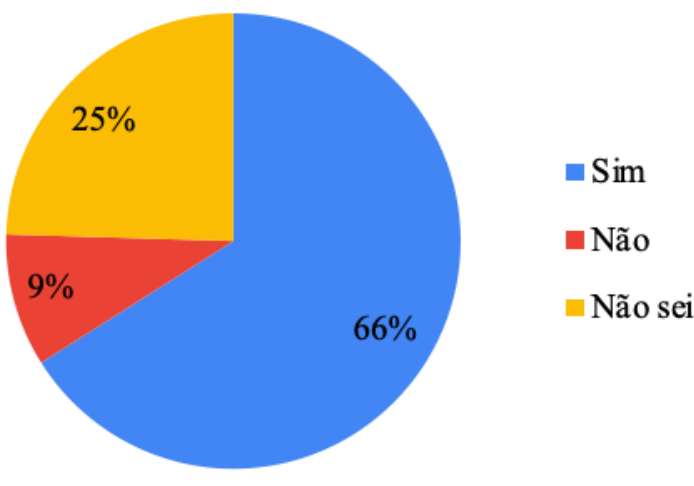

Fonte: Autores (2021).

Por fim, os colaboradores foram questionados se acreditavam que o controle interno poderia favorecer a gestão nos processos cotidianos da empresa. Dentre os 53 colaboradores que responderam à pesquisa, 66\% disseram que sim, 25\% responderam que não e apenas $9 \%$ afirmaram não saber se o controle interno favorece a gestão nos processos habituais da empresa.

\section{Conclusão}

A pesquisa possibilitou identificar que, na generalidade, os colaboradores estão cientes das contribuições e do papel importante que o controle interno desempenha na instituição. Ainda, percebeu-se que uma grande parte dos colaboradores tem uma visão positiva da função e relevância do controle interno na instituição, há uma parcela significativa dos que possuem um conhecimento pouco ou quase nulo do setor e das suas atribuições.

De acordo com as análises realizadas nos processos cotidianos da empresa, ficou nítido que há uma grande preocupação no modo de desenvoltura das atividades, sempre visando conter ou reduzir ao máximo os riscos eminentes. A área de controle interno da organização atua em todas as áreas, sempre planejando, conduzindo e auxiliando nas atividades, garantindo que os objetivos da empresa sejam alcançados de maneira eficaz e sempre dentro da legalidade.

Apesar do controle interno agir de forma geral na instituição, foi possível identificar que há uma necessidade de maior atenção no tocante às práticas de prevenção à fraude e à corrupção. O processo já é aplicado na empresa, porém com um baixo grau de aderência. É aconselhável que haja melhoria não somente na prevenção, mas também na detecção, correção e monitoramento das atividades suscetíveis a práticas corruptas e fraudulentas.

Portanto, é nítido que o controle interno é de considerável importância na administração pública, pois atua diretamente no controle das atividades, assegurando-se de que os propósitos sejam atingidos conforme planejado, agindo não somente na prevenção de fraudes e corrupção, mas também prezando pela eficiência e melhoria nas práticas de gestão e no alcance dos objetivos da instituição.

Como sugestões para trabalhos futuros pode se realizar pesquisas comparando a administração pública em empresas de diferentes ramos de atuação, visando verificar o desenvolvimento destas organizações e a utilização do controle interno como forma de promover melhores resultados.

\section{Referências}

Almeida, M. C. (2010). Auditoria: Um curso moderno e completo - Textos, exemplos e exercícios resolvidos. 7. ed. São Paulo: Atlas. 
Bachtold, C. (2008). Noções de Administração Pública. Cuiabá: EdUFMT; Curitiba: UFPR, 117p.

Brumen, A., Silva, V. L., \& Sales, E. (Coords.). (2015). Controle Interno como Suporte Estratégico de Governança no Setor Público. 1.ed. Belo Horizonte: Fórum. 106p.

Castro, R. P. A. (2014). Sistema de Controle Interno: Uma Perspectiva do Modelo de Gestão Pública Gerencial. 3. ed. ver. E ampl. Belo Horizonte: Fórum.

Costa, M. M. M., \& Terra. R. B. (2008). O papel da administração pública: breves apontamentos sobre a reforma estatal como fomentadora de inclusão social sob o viés de direitos fundamentais, cidadania e o papel do terceiro setor. In: XVII Encontro preparatório para o Congresso Nacional do Conpedi. http://www.publicadireito.com.br/conpedi/manaus/arquivos/anais/salvador/marli_marlene_moraes_da_costa.pdf

Crepaldi, S. A., \& Crepaldi, G. S. (2014). Contabilidade Gerencia: teoria e pratica. 7. ed. São Paulo: Atlas.

Fontes Filho, J. R., \& Alves, C. F. (2018). Mecanismos de controle na governança corporativa das empresas estatais: uma comparação entre Brasil e Portugal. Cad. EBAPE.BR, 16 (1), 1-13. https://www.scielo.br/j/cebape/a/YmWmXVmD6Qz4VLtvsTMz5Db/?lang=pt

Gil, A. C. (2017). Como Elaborar Projetos de Pesquisa. $6^{\text {a }}$ edição. Rio de Janeiro: Grupo GEN.

Gil, A. C. (2021). Como elaborar projetos de pesquisa. 6. ed. São Paulo: Atlas.

Lima, H. M. A. L., Melo, F. A. O., Reis, P. N. C.; Lima, C. C. S., \& Oliveira, V. M. S. (2012). Controle Interno como Ferramenta Essencial Contra Erros e Fraudes Dentro das Organizações. In: Simpósio de Excelência em Gestão e Tecnologia. https://www.aedb.br/seget/arquivos/artigos12/25416604.pdf

Lunkes, R. J. (2007). O Uso de Controles Internos: Um Estudo em Empresas Hoteleiras. In: XXXI EnANPAD, Rio de Janeiro. https://periodicos.ufba.br/index.php/rcontabilidade/article/view/3268

Moura, R. G., \& Barbosa, M. V. (2016). O controle interno e a auditoria como ferramentas eficazes de gestão. In: XII CNEG - Congresso Nacional de Excelência em Gestão. https://www.inovarse.org/sites/default/files/T16_308.pdf

Novo, B. N. (2019). A importância do controle interno na Administração Pública. https://www.direitonet.com.br/artigos/exibir/10996/A-importancia-docontrole-interno-na-Administracao-Publica

Pagliato, W. (2011). Manual de Auditoria - Apresenta as alterações introduzidas pela Lei 11.638 - Nova Leia das S/A. Editora Ciências Modernas LTDA.

Pereira, A. N. (2004). A importância do controle interno para a gestão de empresas. Pensar Contábil, 6(25). http://www.atena.org.br/revista/ojs-2.2.306/index.php/pensarcontabil/article/view/68

Procópio Júnior, P. J., Ferreira, M. C., Ferreira, L. C. A., Silva, D. C., \& Martins, P. L. A Importância do Controle Interno como Ferramenta de Controladoria na Administração Pública. In: IX SEGeT - Simpósio de Excelência em Gestão e Tecnologia, 2012. https://www.aedb.br/seget/arquivos/artigos12/28816537.pdf

Richardson, R. J. (1999). Pesquisa social: métodos e técnicas. 3. ed. São Paulo: Atlas.

Silva, P. G. K. (2002). O papel do controle interno na administração pública. ConTexto, 2(2). https://seer.ufrgs.br/ConTexto/article/view/11555

Silva, T. A. (2017). Conceitos e evolução da administração pública: o desenvolvimento do papel administrativo. In: VIII Seminário Internacional sobre Desenvolvimento Regional, Rio Grande do Sul, p. 1-22. https://online.unisc.br/acadnet/anais/index.php/sidr/article/view/16678

Sinay, M. C. F., Sinay, L., Braga, I. L., Martins, A. C., \& Duarte, A. L. F. Administração pública e fiscalização de concessionárias: um estudo de caso, Research, Society and Development, 9(8), e459985837. DOI: http://dx.doi.org/10.33448/rsd-v9i8.5837 